\title{
ICETh1 and ICETh2, two interdependent mobile genetic elements in Thermus thermophilus transjugation
}

\author{
Ignacio Baquedano, ${ }^{1}$ Mario Mencía, ${ }^{1}$ Alba Blesa, ${ }^{2}$ \\ Vincent Burrus ${ }^{3}{ }^{3}$ and José Berenguerfi ${ }^{1}{ }^{1 *}$ \\ ${ }^{1}$ Centro de Biología Molecular Severo Ochoa (CBMSO), \\ Universidad Autónoma de Madrid-Consejo Superior de \\ Investigaciones Científicas, Madrid, 28049, Spain. \\ ${ }^{2}$ Department of Biotechnology, Faculty of Experimental \\ Sciences, Universidad Francisco de Vitoria, Madrid, \\ 28223, Spain. \\ ${ }^{3}$ Département de Biologie, Université de Sherbrooke, \\ Sherbrooke, QC, Canada.
}

\section{Summary}

Cell to cell DNA transfer between Thermus thermophilus, or transjugation, requires the natural competence apparatus (NCA) of the recipient cell and a DNA donation machinery in the donor. In $T$. thermophilus HB27, two mobile genetic elements with functional similarities to Integrative and Conjugative Elements (ICEs) coexist, ICETh1 encoding the DNA transfer apparatus and ICETh2, encoding a putative replication module. Here, we demonstrate that excision and integration of both elements depend on a single tyrosine recombinase encoded by ICETh2, and that excision is not required but improves the transfer of these elements to a recipient cell. These findings along with previous results suggest that ICETh1 and ICETh2 depend on each other for spreading among $T$. thermophilus by transjugation.

\section{Introduction}

In bacteria, the transfer of genetic material between cells or Horizontal Gene Transfer (HGT) is a key step for bacterial adaptation and evolution (Ochman et al., 2000). This process can be mediated by three major mechanisms: transformation, transduction and conjugation. In the first one, DNA from the extracellular environment is incorporated by cells thanks to specific transformation machinery. Transduction is mediated by bacteriophages

Received 23 August, 2019; revised 10 October, 2019; accepted 17 October, 2019. *For correspondence. E-mail jberenguer@cbm.csic.es; Tel +34-911-964-498. that encapsidate DNA fragments from the host. These fragments can then be inserted into the genome of a new host after infection. In conjugation, DNA is transferred directly from one cell to another through different mechanisms that depend on the phylogeny of the organism. The classic model, or conventional conjugation, has initially been described for model Proteobacteria. The process is mediated by two functional modules, one for DNA processing and replication (Dtr) and the other for mating pair formation (Mpf) (Smillie et al., 2010). The Dtr module involves a cis-acting DNA sequence named the origin for the transfer (oriT) and a relaxase that recognizes the oriT and cuts one of the DNA strands, remaining covalently bound to its $5^{\prime}$ end (Furste et al., 1989). The Mpf module encodes the components of a type IV secretion system that translocates the relaxase-bound ssDNA into a "passive" recipient cell (Koraimann and Wagner, 2014; Cabezón et al., 2015; Christie, 2016). However, unconventional conjugative mechanisms have been described that follow completely different mechanisms and machinery. For instance, in Streptomyces, a single DNA translocase, TraB, is able to recognize the origin of transfer and to form a channel in the membrane through which dsDNA from the donor is transported to the cytoplasm of a recipient cell during intermycelial conjugation (Thoma and Muth, 2015). Also, in Mycobacteria, a poorly characterized mechanism, known as Distributive Conjugal Transfer, allows the simultaneous transfer of different fragments of DNA from the chromosome of a donor to a recipient cell (Gray et al., 2013).

Conventional conjugation is commonly encoded by conjugative plasmids and Integrative and Conjugative Elements (ICEs) (Smillie et al., 2010). The latest are ubiquitous conjugative elements that are integrated at specific sites (attB) in the chromosome of their hosts, usually the $3^{\prime}$ end of tRNA or protein-encoding genes. Under certain circumstances, they can excise from the chromosome, generating an attB site in the chromosome and an attl site on the circularized ICE molecule. Several ICEs have been shown to autonomously replicate prior to transfer to a recipient cell, where they can integrate upon recognition of an attB sequence in the genome (Grohmann, 2010; Lee et al., 2010; Carraro et al., 2015; Wright and Grossman, 2016). 
ICEs range from 20 to more than $500 \mathrm{kbp}$ in size (Johnson and Grossman, 2015) and are composed of different active modules: a DNA processing and transfer module similar to that of conjugative plasmids; a replication module; an integration/excision module; a regulation module that controls the activity of the other modules. ICEs can also bear accessory modules encoding advantageous traits such as antibiotics or heavy metals resistance, or virulence functions, among others (Ghinet et al., 2011; Guglielmini et al., 2011).

The integration/excision module is defined by an integrase, belonging to different families of DNA recombinases (serine recombinases, DDE transposases or, most frequently, tyrosine recombinases) that mediates integration of ICE into the chromosome at specific attB sequences (Wozniak and Waldor, 2010; Bellanger et al., 2014). ICEs that are integrated by tyrosine recombinases often exhibit a high site-specificity; however, there are a few exceptions in which this protein can mediate integration at more than one attachment site (Song et al., 2007; Doublet et al., 2008; Sentchilo et al., 2009; Wood and Gardner, 2015). The integrase also catalyzes the excision, usually with the help of a recombination directionality factor (RDF), also known as an excisionase, which changes the DNA architecture to displace the recombination reaction towards the excision of the ICE (Lewis and Hatfull, 2001). The excision can be stimulated under specific conditions, such as the presence of DNA-damaging agents and sub-lethal concentrations of antibiotics (Wozniak and Waldor, 2010). The replication of ICEs allows them to re-integrate and/or to be mobilized to a recipient cell, where they can integrate either prior or after replication (Lee et al., 2010).

In the thermophilic bacterium Thermus thermophilus, DNA can be transferred in a bidirectional manner between cells that are in direct contact, in a process called transjugation after transformation-dependent conjugation. This process requires the protein TdtA, a membrane-bound DNA translocase, in the donor cell, as well as proteins NurA and Tth111ll that are co- transcribed with TdtA. TdtA forms hexameric rings with an internal hole large enough to accommodate dsDNA. This DNA is actively incorporated by the recipient cell thanks to its highly efficient natural competence apparatus (NCA) (Blesa et al., 2017). How DNA is extruded from the donor cell remains unknown, as there are no genes homologous to those typically described for conjugative systems in other bacteria. TdtA is encoded by an ICE-like element, named ICETh1 thereafter (Figure 1), the first of its class described in T. thermophilus (Blesa et al., 2017).

ICETh1 is 14.8-kbp long, much smaller than conventional ICEs found in Proteobacteria, Bacteroidetes and Firmicutes. It is integrated at the $3^{\prime}$ end of an isoleucine tRNA gene, from which it can be excised (Blesa et al., 2017). TdtA is expressed from a four-gene operon that also includes the restriction enzyme Tth111ll (Zhu et al., 2014), a putative nuclease of the archaeal NurA family, the translocase TdtA and a putative methylase. ICETh1 also carries an integration/excision module that codes for a putative tyrosine integrase.

In this work, we demonstrate that excision/integration of ICETh1 is mediated by an integrase encoded by a second ICE-like element, ICETh2, capable of integration and excision from the chromosome in a way similar to ICETh1. We show that while ICETh1 does not seem to replicate in laboratory conditions, its transfer is impaired when its excision/integration capability is abolished. Finally, we identified in $T$. thermophilus HB8, a strain used as a recipient in transjugation, a third integrative element, ICETh3, which encodes an integrase also active in intracellular mobility of ICETh1. These findings are discussed in the context of general and specific characteristics of Thermus ICEs.

\section{Results}

Genes encoded by ICETh1

Supplementary Table S1 and Figure 1 summarize the distribution of the genes encoded in ICETh1. The

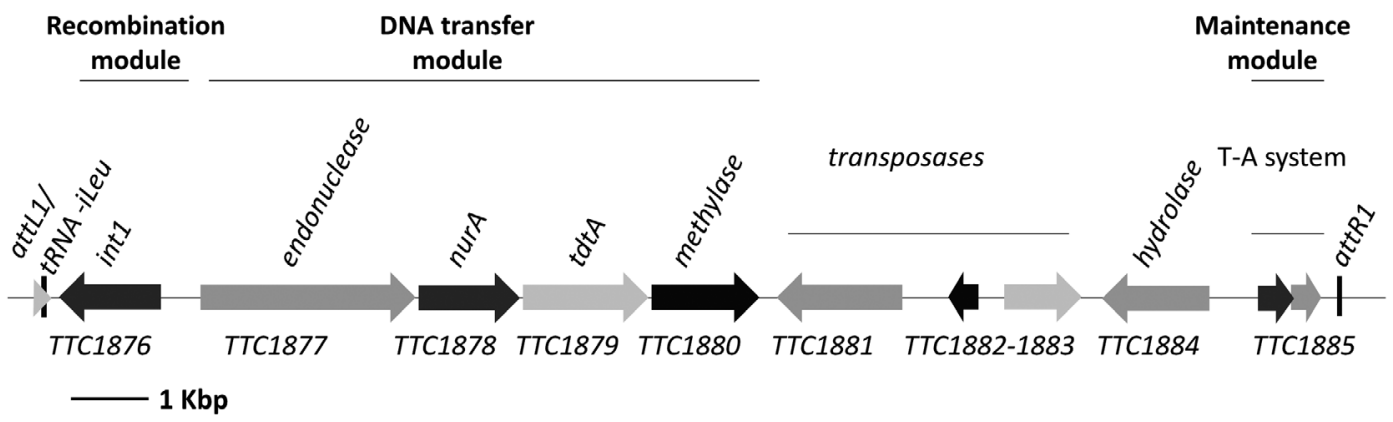

Fig. 1. Schematic representation of ICETh1 integrated in iLeu tRNA and composed of different putative modules. The following modules are proposed for ICETh1: a recombination module composed of Int1, a transfer module composed of a methylase-endonuclease system, a nuclease and a translocase, and a maintenance module formed by a putative toxin-antitoxin system. 
functional assignment of these genes suggests three different modules: excision/integration, DNA transfer, and maintenance. The DNA transfer module is expressed as a four-gene operon that encodes the Tth111ll restrictase (TTC1877), a putative nuclease with several archaeal homologues (NurA, TTC1878), the DNA translocase TdtA (TTC1879) and a putative DNA methylase (TTC1879) (Blesa et al., 2017). Tth1111l, NurA and TdtA have been previously shown to be required for DNA donation in transjugation experiments (Blesa et al., 2017), whereas the involvement of the putative methylase in the process has not yet been studied. The role of a putative maintenance module that codes for homologues of a toxinantitoxin system (TTC1885 and upstream ORF), and of a putative excision/integration module coding for a homologue of tyrosine recombinases (TTC1876, Int1 hereafter) have not been explored. ICETh1 also includes a region with a complete (TTC1881) and two partial (TTC1882 and TTC1883) transposase sequences that have probably been inserted after arrival of ICETh1, as two additional identical copies of the entire transposase are present in the chromosome (TTC0273) and in the PTT27 megaplasmid (TTP0210) of T. thermophilus HB27. Noteworthy is the lack of predicted excisionase gene in ICETh1, suggesting either that an RDF is not required for the excision of ICETh1 by Int1, or that its excision is facilitated by an RDF that is yet to be identified. The role of Int1 of ICETh1 in its excision, integration and transfer to recipient cells during transjugation is analysed below.

\section{Quantitative analysis of the excision of ICETh1}

To further characterize ICETh1 and its intracellular mobility, we quantified its integrated and excised forms in cell cultures using GPCR on the total DNA of samples taken during growth at five different time points, from lag to stationary phases. Specific primers were used to detect the attL1 site of the integrated state (P401-P402), the attB1 scar generated in the chromosome after excision (P338-P339), and the att/1 site on the excised molecule (P401-P417) generated by recircularization of ICETh1 (Table S3). Minor differences in the ratio between the three PCR products were detected throughout the growth, with slightly increased excision detected in stationary phase (Fig. 2A). Copy number per ng of DNA of the different states was analysed on total DNA extracted at the stationary phase (Fig. 2B). Overall, the attL1 site was three orders of magnitude more frequent than the attB1 scar, whereas the att/1 site was even more than ten times less frequent. These data show that excision is a rare event, and suggest that after excision ICETh1 does not replicate, in contrast to conventional ICEs from model bacteria (Grohmann, 2010; Lee et al., 2010; Carraro et al., 2015).
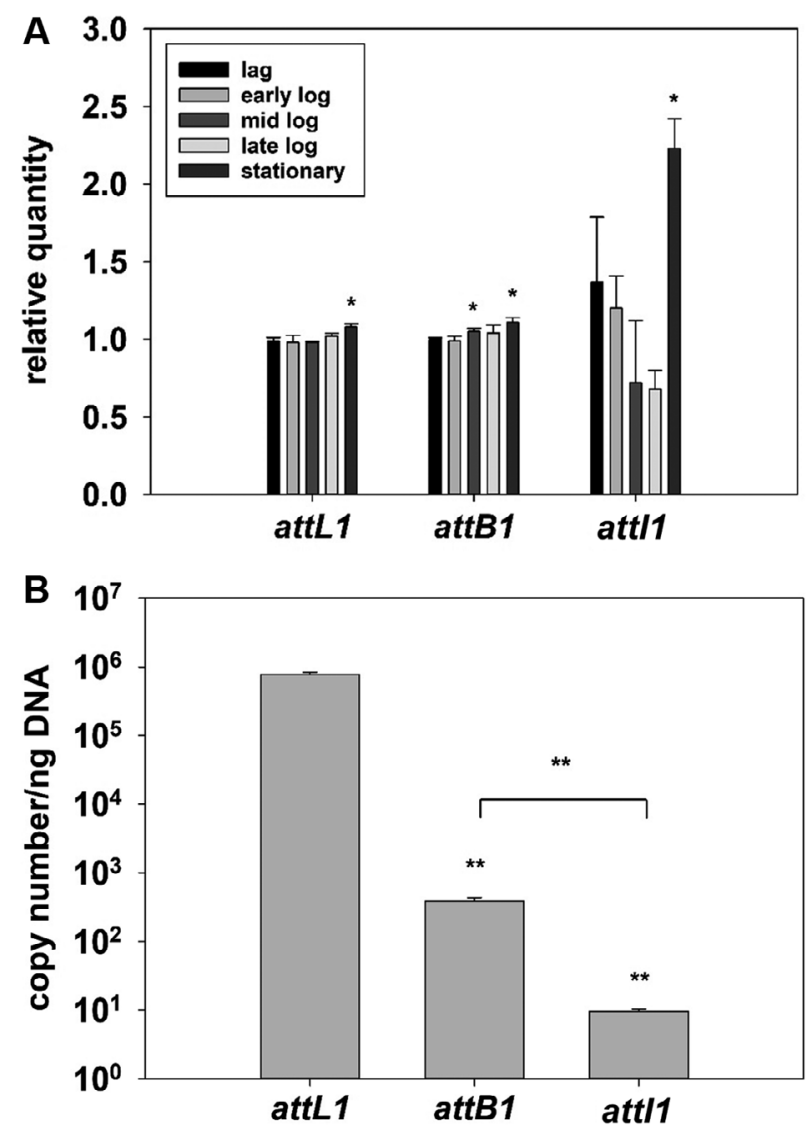

Fig. 2. Detection and quantification of different forms of ICETh1. A. Relative copy number of the different sites of ICETh1: integrated in the chromosome (attL1), the chromosomal scar left after excision (attB1), and circular form (att/1). Cells were harvested throughout cell growth: lag, early-log, mid-log, late-log, and stationary phase. Samples are normalized with $16 \mathrm{~S}$ and polymerase III genes (see Experimental procedures). Asterisks indicate significant statistical differences $(p$-value $<0.05)$ between lag phase and the rest of the phases from the same ICE state group.

B. Quantitative ICETh1 copy number of its different forms in the stationary phase. Asterisks indicate significant statistical differences ( $p$ value $<0.001$ ) between groups.

\section{Transfer of ICETh1 is more efficient than that of chromosomal genes}

To investigate whether ICETh1 transfer was favoured with respect to chromosomal genes, we compared the transfer frequencies of two thermostable antibiotic resistance markers. The first one was inserted in the intergenic region between the hydrolase and the antitoxin genes of ICETh1 (insertion at position $1792493 \mathrm{bp}$ of the genome), and the second one was inserted in the glutamate dehydrogenase gene (TTC1211, $\Delta g d h:: k a t)$. As transjugation between isogenic T. thermophilus HB27 cells is a bidirectional process (Blesa et al., 2015), we used a $\triangle$ pilA4 mutant as the donor cells in these experiments because of its inability to act as recipient (Blesa et al., 2015). The recipient cells used in these 
experiments carried a spontaneous mutation to chloramphenicol for selection. Transjugants of each of the markers were selected using either kanamycin plus chloramphenicol, or hygromycin plus chloramphenicol, and the respective frequencies were compared (Fig. 3A, columns labelled wt). Despite the low frequency of ICETh1 excision and its apparent inability to replicate, the transfer of the ICETh1 (grey bars) was roughly 10 -folds more frequent than that of the chromosomal gene (black bars).

In order to visualize ICETh1 transfer, a thermostable version of GFP (sIFP) (Verdú et al., 2019, in press), expressed from the strong S-layer gene promoter (PslpA), was integrated into the same intergenic region of ICETh1 as in the experiment above (Fig. S1). The surface of recipient cells was covalently labelled with Texas Red succinimidyl ester (Acosta et al., 2012). After transjugation, cells were sorted by flow cytometry to select for double-labelled (green and red) cells and visualized by confocal microscopy. While unselected parental cells appeared either in green (donor) or in red (recipient), transjugants were detected in yellow, showing the transfer of ICETh1 to recipient cells in the absence of a selective marker (Figs $3 \mathrm{~B}$ and $\mathrm{C}$ ).

\section{Int1 is not required for ICETh1 intracellular mobility}

To explore the role of Int 1 in the intracellular mobility of ICETh1, we constructed a $\Delta$ int1 mutant of the element and tested its ability to relocate into a replicative plasmid carrying the attB1 integration site of ICETh1 flanked by 350-bp upstream and downstream sequences (Fig. 4A, plB055). After two rounds of growth on TB agar plates, total DNA was isolated and the integration of ICETh1 in the plasmid target analysed by PCR. Figure 4B demonstrates that despite the absence of int1, ICETh1 was able to relocate on the plasmid, as shown by the 592-bp amplicon obtained with primer pair P451-P482 in both strains (lanes 1 and 3).

\section{ICETh2 provides insertion and excision functions to ICETh1}

The above results led us to search for other genes in the genome of the host strain that could be involved in ICETh1 excision. BlastP searches pointed out to a protein that is highly similar to Int1 (TTC0665, Int2 hereafter), encoded by a gene preceded by a putative RDF coding gene (TTC0664, Exc2 hereafter). Int2 is $98 \%$ identical to
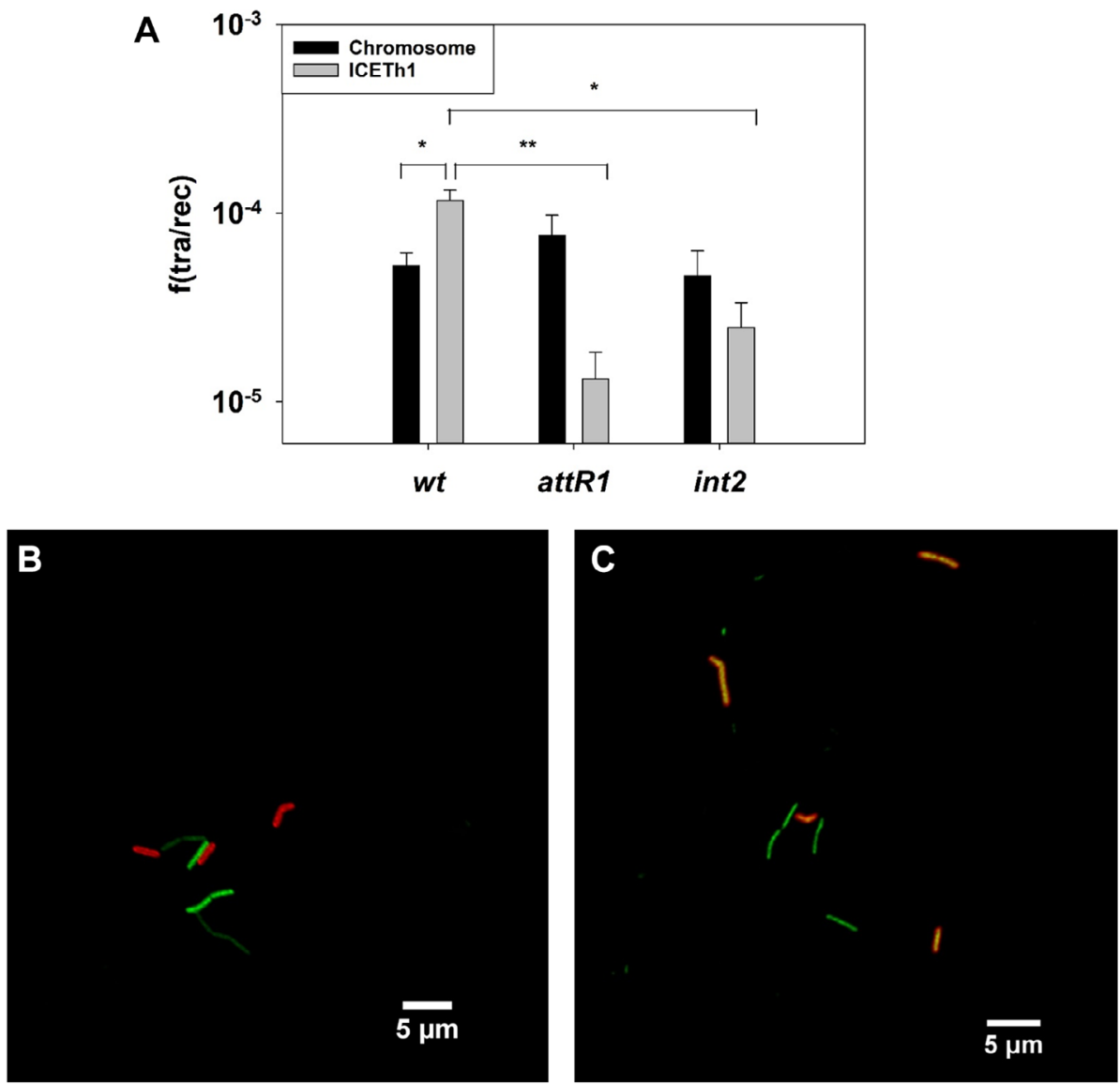

Fig. 3. Transfer of ICETh1 by transjugation.

A. Transjugation frequencies (transjugant CFUs/recipient CFUs) of two different antibiotic resistance markers ( $\mathrm{Km}$ and Hyg) located in the chromosome (black bars) or in ICETh1 (grey bars) in donor strains lacking the attR1 site (attR1), the Int2 recombinase (int2) or the wild-type strain (WT). Recipient cells were selected by chloramphenicol resistance. Asterisks indicate significant statistical differences $\left({ }^{*} p\right.$-value $<0.05 ;{ }^{* *} p$-value $<0.001$ ).

B. Parental cells either expressing sIFP from ICETh1 (green) or labelled at the surface with Texas Red (red). C. Transjugants displaying both fluorophores (yellow) are detected after FACS sorting. Donor cells (green) were also visible. 
A
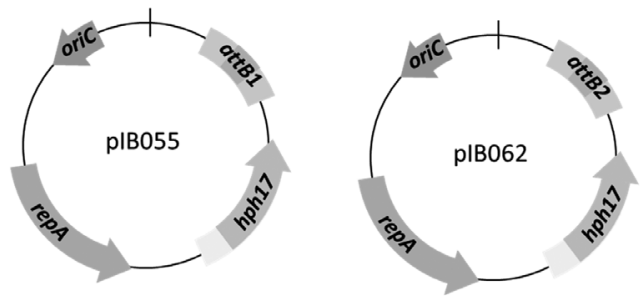

B plB055 pIB062

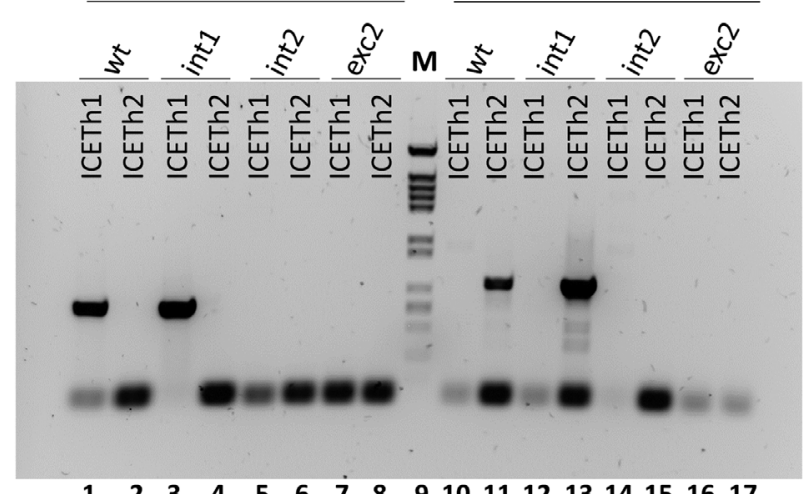

$\begin{array}{lllllllllllllllll}1 & 2 & 3 & 4 & 5 & 6 & 7 & 8 & 9 & 10 & 11 & 12 & 13 & 14 & 15 & 16 & 17\end{array}$

Fig. 4. Intracellular mobility assays for ICETh1 and ICETh2. A. Genetic map of plasmids plB055 and PIB062. Replicative plasmids resistant to Hygromycin B ( $h p h 17)$ were constructed that contained the attachment sites for ICETh1 (attB1) or ICETh2 (attB2). The respective 47-bp sites are shown in darker grey, and the flanking sequences are in lighter colour. In these shuttle plasmids, the repA gene and oriC locus correspond to the replication protein for $T$. thermophilus and the replication origin for Escherichia coli respectively.

B. Ethidium bromide-stained $0.8 \%$ agarose gel of PCR products for the detection of ICETh1 or ICETh2 integration in pIB055 (attB1 site) or pIB062 (attB2 site) in the wild type (WT) or in mutants lacking int1, int2 or the exc2. PCR products of 592 and $781 \mathrm{bp}$ indicate integration of ICETh1 and ICETh2 at their respective attB sites, respectively. Size markers (M) from top (bp): 4370, 2899, 2498, 2201, 1933, 1331, 1150, 759, 611 and 453.

Int1 (Fig. S2), whereas Exc2 contains a predicted helixturn-helix DNA binding motif highly similar to excisionases from Actinobacteria, among others. Interestingly, this putative integration/excision module is encoded at one end of an 11.3-kbp DNA region flanked by $47-$ bp long direct repeats, one of them being the $3^{\prime}$ end of a valine tRNA gene (attR2) (Fig. 5), thereby suggesting a novel integrative element (ICETh2 thereafter). The $\mathrm{G}+\mathrm{C}$ content of ICETh2 is slightly lower than the rest of the chromosome (66\% and $68 \%$ respectively) but higher than that of ICETh1 (59\%). In addition to the putative integration/excision module, similarity searches revealed the presence in ICETh2 of a putative replication module containing a gene that encodes a commercially available DNA primase/polymerase (PrimPol, TTC0656) used in the Trueprime ${ }^{c}$ (Expedeon) DNA amplification kit (Picher et al., 2016), followed by a protein with low similarity to eubacterial DnaG-like primases (TTC0657). In addition, a putative metallopeptidase (TTC0663) is encoded upstream of the exc2 gene (Fig. 5, Table S1). Additional genes encoding putative proteins with no significant homology to proteins in the Genbank database are also located in ICETh2 (Table S1).

As with ICETh1, to determine whether ICETh2 was actually an excisable element, PCR assays were carried out to identify the integrated element (attL2 and attR2), its excised form (att/2), and the chromosomal "scar" (attB2) resulting from excision. Similarly to ICETh1, the results, shown in Figure $6 \mathrm{~A}$, demonstrate that an ICETh2-free form of the chromosome (attB2) and circular ICETh2 (att/2) form were detected (lanes 4 and 5), and confirmed the nature of ICETh2 as a bona fide integrative element. Further qPCR quantification of the three ICETh2 states revealed that the integrated form was five orders of magnitude more abundant than the excised one or the chromosomal scar (attB2), which reached similar levels (Fig. 6B).

To test if Int2 or Exc2 were required for the intracellular mobility of ICETh1 and/or ICETh2, knockout mutants were constructed. Also, to test the specificity of integration, a new replicative plasmid (plB062) containing the attB2 site and 350-bp flanking sequences was constructed (Fig. 4A) and transformed in parallel with plB055 (with attB1 site) into the wild-type strain and its $\Delta$ int1, $\Delta$ int2 and $\Delta$ exc2 mutants. The strains transformed with each plasmid were analysed by PCR. As shown in Figure 4B, ICETh1 and ICETh2 integration in pIB055 and pIB062 respectively, was detected in both the wild-type strain and its $\Delta$ int1 mutant (lanes 1, 3, 11 and 13). However, relocation of either ICETh was undetectable in the $\Delta i n t 2$ or $\Delta$ exc2 mutants (lanes 5-8 and 14-17). Remarkably, each ICETh integrated specifically at their respective attB sites, ICETh1 into attB1 and ICETh2 into attB2 and no crossed integration was detected in the wild-type strain under the assay conditions (lanes 2 and 10). Noteworthy, previous versions of plB055 and plB062 harbouring only $100 \mathrm{bp}$ of flanking DNA of the attB sites were found to be unsuitable target sites for insertion, as no integration of ICETh could be detected (data not shown). These data suggest that Int2 and Exc2 from ICETh2 are required for the intracellular mobility of both ICETh1 and ICETh2 and that those 350-bp flanking sequences around the attB sites are essential for integrase recognition.

\section{A hybrid mini-ICETh is functional in an heterologous T. thermophilus host}

To confirm that int2-exc2 module mediates the intracellular mobility of ICETh1, a new replicative plasmid harbouring a hybrid minimal ICETh was constructed (pMoT-Minimal-ICETh1). This plasmid included the 


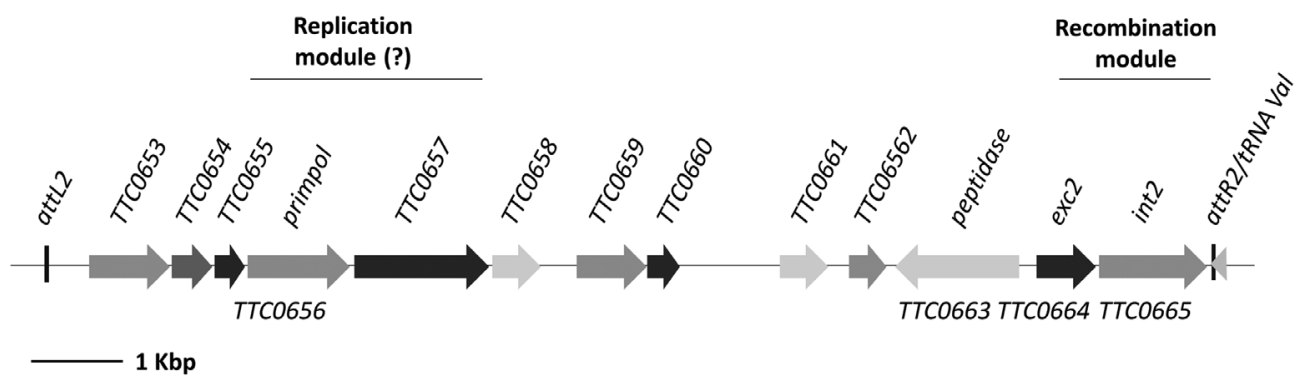

Fig. 5. Schematic representation of ICETh2 integrated in Val tRNA sequence. Recombinase Int2 and Exc2 could form a recombination module. A peptidase, a primase and a primase polymerase are also encoded in this mobile genetic element, tentatively assigning them to a replication module.
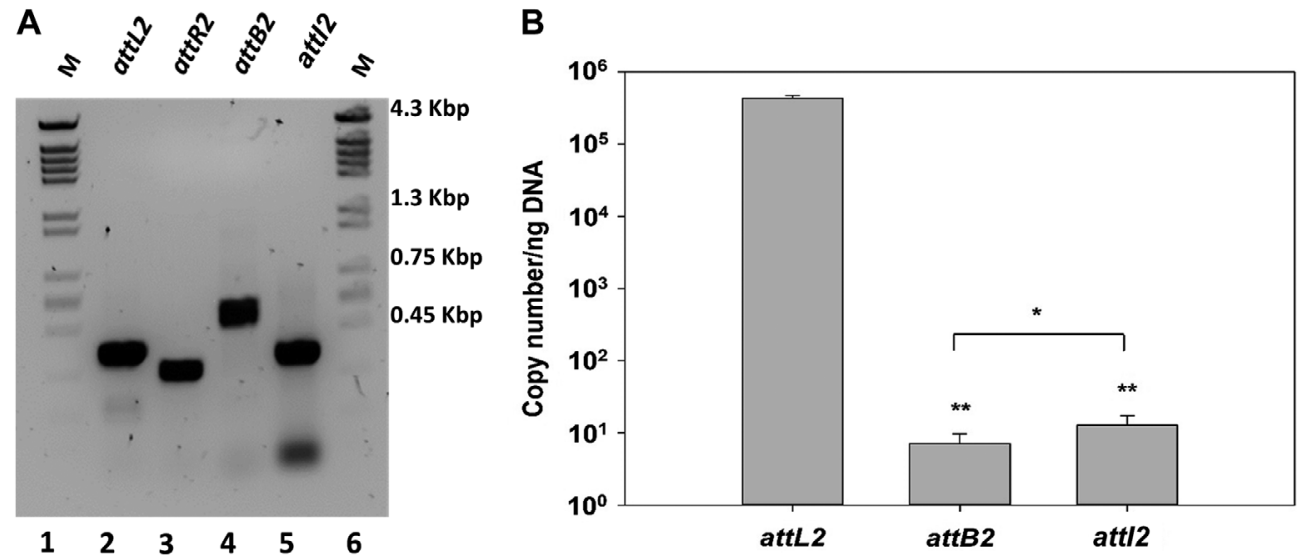

Fig. 6. ICETh2 is a mobile element.

A. PCR analysis ICETh2 states: Integrated (attL2 and attR2) form was detected by amplification of 362- (lane 2) and 290-bp (lane 3) PCR products, respectively; The scar (attB2) in the chromosome (lane 4) and the attl site in the excised ICE (lane 5) produced 481 and 351 bp PCR products, respectively. For attl, a nested PCR has been performed. All PCR products were sequenced.

B. Quantification of the different forms of ICETh2 in the stationary phase. The integrated, (attL2) and the excised (att/2) states along the chromosomal scar (attB2) generated after ICETh2 excision were quantified by qPCR (copies $\mathrm{ng}^{-1}$ of DNA). Asterisks indicate significant statistical differences ( ${ }^{*} p$-value $<0.05 ;{ }^{* *} p$-value $<0.001$ ).

exc2-int2 genes from ICETh2 and a thermostable antibiotic resistance marker between the attR1 and attL1 sites from ICETh1 (Fig. 7A). As a control, a similar plasmid was constructed (pMoT-Minimal-ICETh1-YFRQ) that encodes an Int2 variant mutated in two conserved residues that are required for activity in recombinases from the same family (Y364F and R331Q) (Esposito and Scocca, 1997). Both plasmids were transformed in $T$. thermophilus HB8, a natural strain devoid of ICETh1. However, genome sequence searches of this strain revealed the presence of yet another putative integrative element (ICETh3) inserted at the same target site as ICETh2 was in the HB27 strain (val-tRNA). Moreover, this new putative ICETh3 also encodes an integrase (TTHA1027, Int3 hereafter) with high identity to Int1 and Int2 (Fig. S2), and such int3 gene is preceded by a putative RDF gene (exc3 hereafter). Therefore, a $\Delta$ int3 deletion mutant of the $T$. thermophilus HB8 strain was also constructed and used as a host in parallel to the wild type to avoid putative interferences in the integration experiments. After the transformation of both strains with the plasmids encoding active and inactive forms of Int2, DNA was purified and PCR performed to detect integration within the ileu-tRNA gene (attB1, identical to that of the HB27 strain) of this minimal version of ICETh1. As shown in Figure 7B, integration of both forms of this mini-ICETh1 was detected in the T. thermophilus HB8 wild-type strain (lanes 1 and 2), as revealed by the detection of the expected 650-bp amplicon. However, in the $\Delta$ int 3 mutant only the ICETh1 form of the plasmid expressing the wild-type form of Int2 was integrated (lane 3), whereas in the $\Delta i n t 3$ strain carrying a plasmid with an inactive Int2 protein no integration was detected (lane 4). These data demonstrate that Int2, as well as the new recombinase Int3 can mobilize the repeats of ICETh1. 

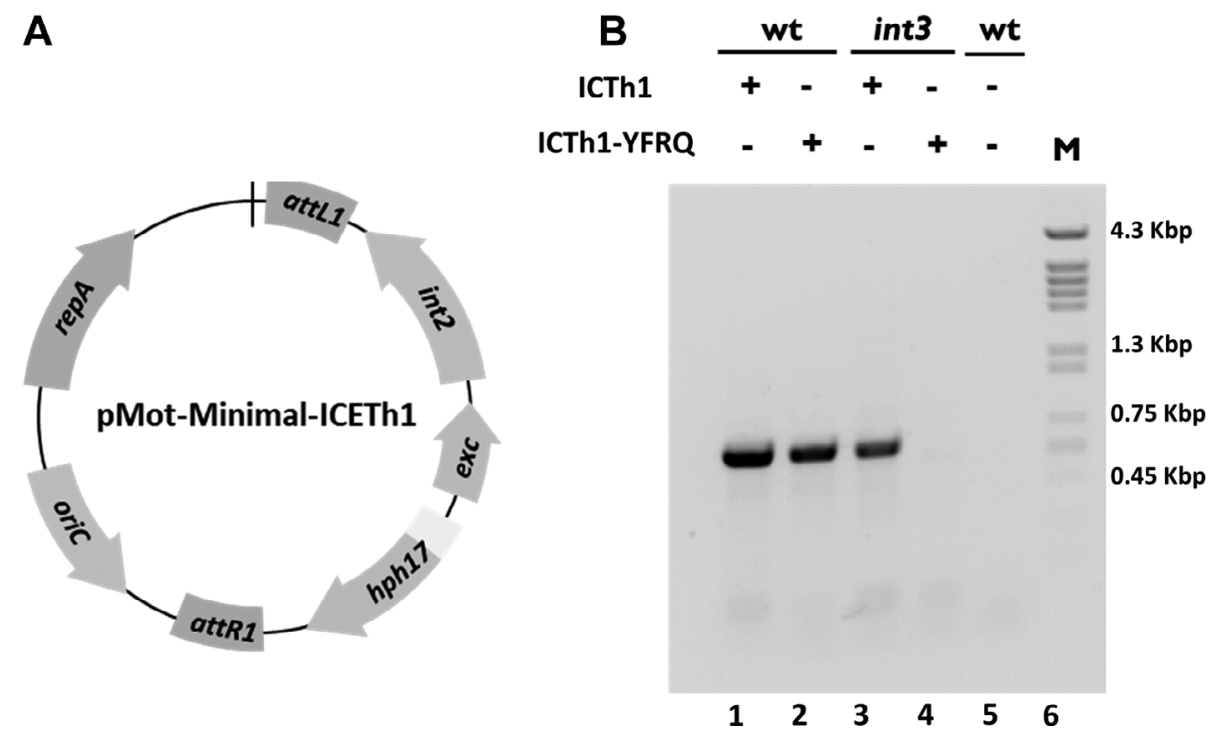

Fig. 7. Intracellular mobility of a minimal-ICETh1 in a heterologous host. A. Plasmid pMot-Minimal-ICETh1. Genetic map of the E. coli-T. thermophilus shuttle plasmid carrying the minimal regions required for ICETh1 intracellular mobilization in a heterologous host containing the attB1 site. The genes encoding the excisionase (exc2) and the integrase (int2) of ICETh2 are included between the attL1 and attR1 sites of ICETh1. A marker for hygromycin resistance (hph17) was included for selection.

B. PCR analysis of the integration of Minimal-ICETh1 in the attB1 site (Ile tRNA gene) of $T$. thermophilus HB8. Plasmids pMot-Minimal-ICE or pMot-Minimal-ICE-YFRQ were transformed in wild type cells of $T$. thermophilus HB8 (WT) or in its derivative lacking Int3 (int3). Positive insertion was revealed by the amplification of a 650-bp product. The presence of the indicated plasmid is depicted with + symbol and no presence with symbol.

\section{Excision of ICETh1 is not required but favours transjugation}

In some instances, the conjugation machinery is transcribed only after excision from the chromosome of conventional ICEs, in such a way that excision-deficient mutants show little or no transfer (Bañuelos-Vazquez et al., 2017). Given that the expression of the $t d t A$ operon from ICETh1 is required for transjugation (Blesa et al., 2017), we checked if transjugation was possible in the absence of excision. To do this, transjugation assays were performed with two mutants defective in ICETh1 excision, one lacking its attR1 site and the other lacking Int2, the integrase shown above to be needed for ICETh1 excision. Also, in order to avoid bidirectional transjugation, these mutations were included in a $\Delta$ pilA4 genetic background used as above as unidirectional donor strain (Blesa et al., 2017). Transfer efficiencies for ICETh1 and for chromosomal markers ( $g d h$ or TTC0313 genes) were analysed. As shown in Figure 3A, the transfer of the chromosomal markers was not affected by the inability of ICETh1 to excise (black bars) when compared with the excision-proficient strain. However, the transfer of ICETh1 was significantly impaired in the two excisiondeficient mutants (grey bars) respect to the excisionproficient strain (labelled wt). Therefore, whereas the excision of ICETh1 is not relevant for transjugation of chromosomal genes, it is important for its own transfer.

\section{Discussion}

In a previous study, we identified an integrative element (ICETh1) in T. thermophilus HB27 as the mobile element responsible for the DNA donation capability in transjugation, a special type of unconventional conjugative process dependent on the NCA of the recipient cell (Blesa et al., 2017). ICETh1 has a relatively low $G+C$ content, thereby supporting its recent acquisition by HGT. It can be excised from the chromosome as a circular form and confers efficient DNA donation capability upon its transfer to the HB8 strain (Blesa et al., 2017). Here, we studied the frequency of this excision, the genes involved in this process and their relation with the mobilization capability of the element. Unexpectedly, we identified along this study a second ICE-like element, ICETh2, which shares its excision/integration function with ICETh1, facilitating transfer of the latter to recipient cells.

\section{Int1 is apparently inactive}

Analysis of the genetic structure of ICETh1 pointed to the existence of a dedicated tyrosine integrase-Int1-that was the most likely candidate for the excision and integration of the element. However, in an intracellular mobility assay to a plasmid target, an ICETh1 mutant lacking int1 remained as mobile as in the wild type (Fig. 4B), 
suggesting that another recombinase in the cell provided the functional redundancy that complemented the mutation. Int2, a homologue sharing $98 \%$ of identity with Int1, was found to be encoded by another small integrative element named ICETh2 that is located in another chromosomal region (Fig. 5). Since the intracellular mobility of both ICEs was abolished in the int2 mutant (Fig. 4B), we concluded that (i) int1 is inactive, and (ii) Int2 was able to recognize the specific att sites of both ICEThs.

The apparent irrelevance of Int1 is a puzzling result, as sequence alignment of Int1 and Int2 (Fig. S2) did not reveal any significant amino acid difference that could support it. Actually, the six amino acid substitutions detected with respect to Int2 (R1K, R95Q, H190Q, G249R, V253A and K319R) did not affect the catalytic residues described for tyrosine recombinases (Esposito and Scocca, 1997). In addition, most of these amino acid changes (R95Q, H190Q, G249R, V253A and K319R) were also present in Int3, a third homologue found in $T$. thermophilus HB8, shown to be active in the integration of an artificial mini-ICETh1 (Figure 7B). Therefore, we suggest that the inactivity of Int 1 is likely due to a lack of expression. However, since qRT-PCR assays on int1 and int2 genes show that both genes are transcribed at low levels (Fig. S3), the lack of Int1 activity rather suggests defective translation. Indeed, whereas int2 and its homologue int3 have identical upstream sequences characterized by the presence of a canonical Shine-Dalgarno (AGGAGG) for Thermus at an appropriate distance (-11) with respect to the ATG start codon, int1 has a suboptimal Shine-Dalgarno sequence (GAGGG) at the corresponding position, suggesting a lower translation efficiency under our experimental conditions.

An alternative explanation regarding the requirement for an excisionase as the reason for Int1 inactivity seems unlikely, as the high sequence identity shared by Int1 and Int2 supports that Exc2 should also be acting on Int1 for the mobility of ICETh1, and this is not the case (Fig. 4).

\section{An active excisionase is required for ICETh1 and ICETh2 excision}

The putative exc genes located upstream of int2 and int3 exhibit $97 \%$ identity and code for proteins containing a highly conserved helix-turn-helix motif in their C-terminal domain shared by proteins described as excisionase in several phyla. Our data demonstrate that exc2 is required for the intracellular mobility of ICETh1 and ICETh2 in $T$. thermophilus HB27, likely playing a similar function to that of RDF described for other mobile genetic elements (Marra and Scott, 1999; Lewis and Hatfull, 2001). However, it is worth mentioning that the large distance (120 bp) between the stop codon of exc genes and the start codon of their cognate int genes suggests expression from independent promoters.

A single recombinase mediates site-specific integration of two different ICEThs at different sites

The integration of several ICEs in more than one attachment site has been described, as some mismatches are tolerated by the site-specific recombinases within the recombination core region. In most cases, this apparent site promiscuity was detected in mutants lacking the normal att site. For example, SGl1 from Salmonella enterica can integrate into secondary att $B$ sites when thd $F$, its primary integration site, is not present (Doublet et al., 2008). Also, the SXT element of Vibrio cholerae is able to integrate at alternative sites in the absence of prfC, its primary integration site (Burrus and Waldor, 2003). Target promiscuity in different tRNA $A_{\text {Gly }}$ has been also shown for ICEclc from Pseudomonas knackmusii (Sentchilo et al., 2009).

In $T$. thermophilus, the recombinase Int2 integrates both ICETh1 and ICETh2 into their respective attB target sites in a specific manner (Fig 4B). A third recombinase, Int3, which is almost identical to Int1, integrates the miniICETh into the specific attB1 site in T. thermophilus HB8, despite being encoded by the putative ICETh3 that is integrated at a different attB site, identical to attB2. Therefore, a single integrase can recognize different attl sites, in a rather promiscuous way, while being able to recombine them in a site-specific way in the presence of the cognate attB target. A comparison of the attB sites shown to be recognized in vivo by Int2 (Figure 8 ) shows the strict conservation of a 7-bp recombination core (ACTTGAA), while SNPs exist in the inverted repeat arms that surround the recombination core and likely serve as recombinase binding sites. This suggests that the surrounding sequences could be relevant for the discrimination of their cognate integration sites. However, the possibility that the ICEThs could integrate at alternative att $B$ sites in the absence of their primary target site cannot be ruled out.

In addition, similarly to other recombinases (Biswas et al., 2005), sequences upstream and downstream of the 47-bp att sites are required for the integration reaction, since, when these regions were not large enough, integration was not detected (data not shown). In other experimental systems like CTnBST from Bacteroides spp., the tyrosine recombinase IntBST also exhibits recombination specificity for different targets and requires 270-bp extensions of attBST for integration (Song et al., 2007). Furthermore, conjugative transposon CTnDOT of Bacteroides spp. is able to target six different attB sites that contain the conserved sequence TTTGC at the core (Wood and Gardner, 2015). 


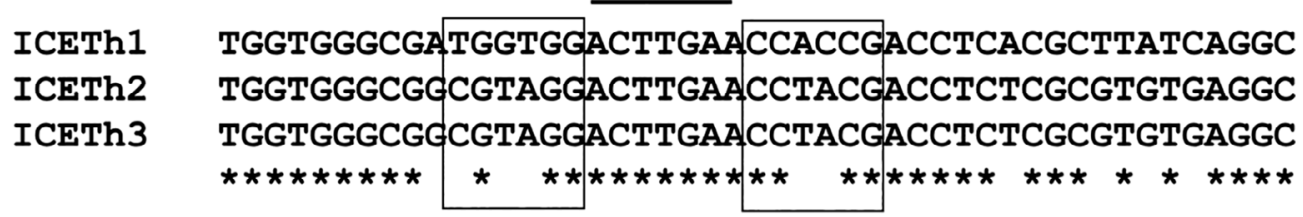

Fig. 8. Alignment of the attB sites the ICETh1-3 from T. thermophilus. Boxes indicate the inverted regions and the line indicates the recombination core.

Therefore, despite the apparent odd fact that a single recombinase, Int2, is able to excise and integrate different ICEs to their specific attB target, similar observations have been made in a few mesophilic model systems. This effect is likely due to the ability of the recombinases to recognize a core sequence and at the same time displaying some tolerance to vis-a-vis substitutions in the surrounding sequences. Alternatively, the topology of DNA around the target site could play a major role in recognition.

\section{Excision favours transfer of ICETh1 rather than genomic DNA}

Our results suggest that there is no active replication of ICETh1 after excision, as the excised state is at least one order of magnitude less frequent than the chromosomal scar (attB1, Fig. 2B), suggesting that loss of ICETh1 occurs in a dividing cell population. This is somehow contradictory with the data that show that a marker inserted in ICETh1 is transferred to a recipient cell with much higher frequency (one order of magnitude approx.) than a chromosomal marker. Furthermore, ICETh1 transfer was detected using a fluorescent marker, in the absence of strong selective pressure by antibiotic resistance, supporting this high transfer efficiency and easy spreading within the cell population.

The mechanism favouring higher transfer of ICETh1 when it is excisable over genomic DNA is for now unknown. However, it could be related to its circular nature that could make it a better substrate for the transfer machinery and likely involve specific recognition of the circular ICETh1 DNA by the mating apparatus.

\section{Concluding remarks}

Here, we have shown that two small ICEThs coexist in Thermus thermophilus HB27 and that the efficient spreading of ICETh1, encoding the DNA transfer capability required for transjugation, depends on the activity of the integration/excision module encoded by ICETh2. This dependence does not affect the specificity for their respective targets, thus precluding putative competition within its host. Conversely, ICETh1 contributes to the spreading of ICETh2 through the functions of its transfer module. A third ICE (ICETh3) identified in another host can also supply an integration function to ICETh1 when this enters into the HB8 strain, suggesting a frequent collaborative strategy among different ICEThs. Likely, this cooperativity could favour the scale down of each ICETh individual size in a high-temperature environmental context in which the burden for accurate DNA replication is highly selective. Therefore, instead of having large complete ICEs encoding all the modules needed for the excision, replication and spreading by conjugation, hightemperature environments may have favoured functional distribution of modules in partial-ICEs likely co-selected during evolution. Despite being smaller than conventional ICEs these elements like ICETh1 and ICEth2 behave as complete ones and should be considered a new class of ICE.

Still, many questions remain to be answered in future works regarding these ICEThs, such as the role of a putative replication module in ICETh2 along with the function of the protease and the toxin-antitoxin system of ICETh1 that could guarantee the stability of this element in its host.

\section{Experimental Procedures}

\section{Bacterial strains and growth conditions}

Table S2 describes the bacterial strains used in this study. Escherichia coli $\mathrm{DH} 5 \alpha$, used for cloning purposes, was grown at $37^{\circ} \mathrm{C}$ in Luria-Bertani (LB) medium. Thermus thermophilus strains were grown at $60^{\circ} \mathrm{C}$ or $65^{\circ} \mathrm{C}$ in TB (Thermus broth, Trypticase $8 \mathrm{~g} \mathrm{~L}^{-1}$, Yeast extract $4 \mathrm{~g} \mathrm{~L}^{-1}, \mathrm{NaCl} 3 \mathrm{~g} \mathrm{~L}^{-1}$ in carbonate-rich mineral water) under rotational shaking (180 rpm). For plates, agar $2 \%$ (w/v) was used. Kanamycin ( $\left.\mathrm{Km}, 30 \mu \mathrm{g} \mathrm{m}^{-1}\right)$, Ampicillin (Amp, $100 \mu \mathrm{g} \mathrm{ml}^{-1}$ ), Hygromycin B $\left(\mathrm{Hyg}, 100 \mu \mathrm{g} \mathrm{ml}^{-1}\right.$ ) or Chloramphenicol $\left(\mathrm{Cm}, 20 \mathrm{\mu g} \mathrm{ml}^{-1}\right)$ were added for selection when needed.

\section{Generation of bacterial mutants}

The plasmids used in this work are listed in Table S3. Plasmids used for the isolation of deletion mutants through double recombination were constructed in $E$. 
coli vectors by placing upstream and a downstream recombination arms respect to the targeted gene, separated by a selectable gene cassette conferring thermostable resistances either to $\mathrm{Km}$ (kat) or to Hyg ( $h p h)$ as described (Blesa et al., 2017). Oligonucleotides used for the amplification of the recombination arms are described in Table S4. The plasmids for the isolation of mutants constructed were used to transform $T$. thermophilus, and the mutants were selected on TB plates with $\mathrm{Km}$ or $\mathrm{Hyg}$, leading to the replacement of the gene of interest for the corresponding antibiotic resistance. Transformants were streaked at least twice on selection plates to avoid the presence of wild-type copies of the targeted gene in this polyploid bacterium (Ohtani et al., 2010). For spontaneous mutants, approximately $10^{8}$ cells of the parental strain were plated on TB plates containing $\mathrm{Cm}$. For the insertion of the reporter gene encoding a fluorescent thermostable protein (sIFP) or an antibiotic marker, the same double recombination strategy was used.

\section{Transformation and transjugation assays}

Transformation of $T$. thermophilus was carried out as described elsewhere (De Grado et al., 1999). Briefly, mid-exponential cultures were transformed with $100 \mathrm{ng}$ of DNA. After 4-h incubation at $65^{\circ} \mathrm{C}\left(60^{\circ} \mathrm{C}\right.$ in the case of hph resistance cassette), cultures were plated on agar TB plates with the desired antibiotic.

For transjugation assays, the protocol described by Blesa et al., (2015) was used with minor modifications. Two-hundred microliters of saturated cultures of both parental cells ( $\mathrm{Hyg} / \mathrm{Km}$ resistant) were washed in one volume of TB, resuspended in $10 \mu \mathrm{l}$ of TB in presence of DNase I (5 units, Roche) and applied onto sterile $0.22 \mu \mathrm{m}$ nitrocellulose filters (GSWP, Millipore) placed on top of TB agar plates that were further incubated for $4 \mathrm{~h}$ $30 \mathrm{~min}$ at $60^{\circ} \mathrm{C}$. Cells were then detached from filters by vigorous shaking in TB, and the desired dilutions were plated on selective TB plates, which were incubated at the same temperature. Transjugation frequencies were expressed as CFU of transjugants per CFU of recipient cells. Three independent assays were performed for each transjugation assay.

For microscopy observation of the transfer of the SIFP marker, saturated cultures of donor and recipient cells were diluted to $\mathrm{OD}_{600}=0.05$ and grown on TB. At the exponential growth phase, the recipient cells were labelled at the surface with Texas Red as described below, and both populations were mated as described above. After incubation, the mating mixture was detached from the filter and processed as indicated in the Sorting and Confocal Microscopy section.

\section{In vivo fluorescent staining}

One millilitre of cells grown to exponential phase were centrifuged and re-suspended in the same volume of PBS. Then, $10 \mu \mathrm{l}$ of a $5 \mathrm{mg} \mathrm{ml}^{-1}$ solution of Texas Red succinimidyl ester (Molecular Probes Europe BV, Leiden, The Netherlands) in dimethyl sulfoxide was added, keeping the cells for $20 \mathrm{~min}$ at $65^{\circ} \mathrm{C}$ in the dark to complete the labelling. The addition of $100 \mathrm{mM} \mathrm{Tris-HCl} \mathrm{pH}$ 8 stopped the reaction. Finally, the cells were centrifuged and washed twice in PBS before being used in the transjugation experiments.

\section{Sorting and confocal microscopy}

Sorting of mated cells labelled with fluorescent dyes and the sIFP was performed after washing with PBS of the mating mix and fixation with $1 \%(\mathrm{w} / \mathrm{v})$ of paraformaldehyde. Sorting was performed with FACSAriaTM Fusion equipment (Becton Dickinson). sIFP was excited at $488 \mathrm{~nm}$ and emission was recorded with $530 / 30 \mathrm{~nm}$ filter, while Texas Red was excited at $562 \mathrm{~nm}$ and its emission was recorded at $610 / 20 \mathrm{~nm}$. Cell populations selected were laid onto microscope slide coated with $0.01 \%$ polyL-lysine, then covered with Mowiol-treated coverslips. Images were acquired with Nikon A1R coupled to Eclipse Ti-E (Nikon) inverted microscope. Images were taken with $60 \times / 1.4$ oil Plan-Apochromat immersion objective under 488 and $561 \mathrm{~nm}$ lasers. Images were processed with Huygens 18.1.0p7 64b (S.V.I.) software.

\section{$D N A$ and RNA extraction and quantitative $P C R$}

Three to five independent replicates of each sample were processed as follows. Genomic DNA was extracted using DNeasy ${ }^{\circledR}$ blood and tissue kit (Qiagen) following the manufacturer's instructions for Gram-negative bacteria. DNA quantity and integrity were measured using Nanodrop ${ }^{\text {TM }}$ One (ThermoFisher).

RNA was isolated using RNeasy Mini Kit (Qiagen) under the manufacturer's instructions followed by DNAse I treatment (RQ1, Promega). RNA was quantified in a Nanodrop One spectrophotometer and RNA integrity was checked with the Agilent 2100 Bioanalyzer. RT reactions were performed using the iScript CDNA Synthesis kit (Biorad PN170-8891) following the manufacturer's instructions.

QPCR reactions were performed in 384-well plates in $10 \mu \mathrm{l}$ final volume. Different samples were tested: nontemplate control, efficiency curve points, standard curve points and problem samples. Putative reference genes analysed were 16S (TTC3084), DNA polymerase III (TTC1806) and RNA polymerase alpha subunit (TTC1300). Primers used for amplification are indicated 
in Table S4. The master mix reagents were added as follows: $1 \mu \mathrm{l}$ of primer mix $(5 \mu \mathrm{M}$ of each primer) $+5 \mu \mathrm{l}$ Power SYBR ${ }^{\circledR}$ Green PCR Master Mix (Thermo Fisher Scientific, CN 4367659), which includes AmpliTaq Gold ${ }^{\circledR}$ DNA Polymerase, dNTPs and the rest of components needed to perform the PCR. Reactions were set up manually taking into account precautions necessary to avoid contamination with the amplicons. Reactions were performed in a CFX384 Real-Time System C1000 Thermal Cycler (Bio-Rad), in hard-Shell ${ }^{\circledR}$ 384-Well PCR Plates White Well Clear shell (Bio-Rad CN HSP-3805). For RTPCR, gDNA contamination was assessed by amplification of RT controls of the samples.

Technical triplicates were performed in order to correct pipetting errors in plate loading. In general, accurate technical repeats were obtained. To correct the efficiency of genes of interest, the efficiency value used was obtained in the standard curves.

PCR relative quantification of the data was carried out using software GenEx v.5.4.4. (MultiD Analyses AB, Gothenburg, Sweden). Data absolute quantification processing was carried out using software Microsoft Excell 2010 (after correction of efficiency of $\mathrm{Cq}$ values in software GenEx).

\section{Bioinformatics}

Protein domains were identified using the Pfam database. Blast analyses were performed with the UniProtKB database for protein and BLAST $^{\circledR}(\mathrm{NIH})$ for DNA sequences. Multiple sequence alignments were performed using Clustal Omega (EMBL-EBI). $G+C$ content of ICETh2 was assessed with the $\mathrm{G}+\mathrm{C}$ Content Calculator (Biologics International Corp). Statistical analyses were performed with SPSS ${ }^{\circledR}$ Statistics v. 25 (SPSS, Chicago, IL, USA; 2008), considered statistically significant for $p$-values $<0.05$.

\section{Acknowledgements}

This work was supported by a grant from the Spanish Ministry of Science, Innovation and Universities [BIO2016 -77031-R] to J.B. and a Discovery Grant [2016-04365] from the Natural Sciences and Engineering Council of Canada (NSERC) to V.B. I.B. is the holder of a competitive FPI contract. An institutional grant from Fundación Ramón Areces to the CBMSO is also acknowledged.

\section{References}

Acosta, F., Alvarez, L., de Pedro, M.A., and Berenguer, J. (2012) Localized synthesis of the outer envelope from Thermus thermophilus. Extremophiles 16: 267-275.
Bañuelos-Vazquez, L.A., Torres Tejerizo, G., and Brom, S. (2017) Regulation of conjugative transfer of plasmids and integrative conjugative elements. Plasmid 91: 82-89.

Bellanger, X., Payot, S., Leblond-Bourget, N., and Guédon, G. (2014) Conjugative and mobilizable genomic islands in bacteria: Evolution and diversity. FEMS Microbiol Rev. 38: 720-760.

Biswas, T., Aihara, H., Radman-Livaja, M., Filman, D., Landy, A., and Ellenberger, T. (2005) A structural basis for allosteric control of DNA recombination by $\lambda$ integrase. Nature 435: 1059-1066.

Blesa, A., Baquedano, I., Quintáns, N.G., Mata, C.P., Castón, J.R., and Berenguer, J. (2017) The transjugation machinery of Thermus thermophilus: Identification of TdtA, an ATPase involved in DNA donation. PLoS Genet. 13: 1-22.

Blesa, A., César, C.E., Averhoff, B., and Berenguer, J. (2015) Noncanonical cell-to-cell DNA transfer in Thermus spp. Is insensitive to argonaute-mediated interference. J Bacteriol 197: 138-146.

Burrus, V., and Waldor, M.K. (2003) Control of SXT integration and excision. J Bacteriol 185: 5045-5054.

Cabezón, E., Ripoll-Rozada, J., Peña, A., de la Cruz, F., and Arechaga, I. (2015) Towards an integrated model of bacterial conjugation. FEMS Microbiol Rev 39: 81-95.

Carraro, N., Poulin, D., and Burrus, V. (2015) Replication and active partition of Integrative and conjugative elements (ICEs) of the SXT/R391 family: the line between ICEs and conjugative plasmids is getting thinner. PLOS Genet 11: e1005298.

Christie, P.J. (2016) Mosaic type IV secretion systems. EcoSal Plus 7: 1-34.

De Grado, M., Castán, P., and Berenguer, J. (1999) A hightransformation-efficiency cloning vector for Thermus thermophilus. Plasmid 42: 241-245.

Doublet, B., Golding, G.R., Mulvey, M.R., and Cloeckaert, A. (2008) Secondary chromosomal attachment site and tandem integration of the mobilizable Salmonella genomic island 1. PLoS One 3: e2060.

Esposito, D., and Scocca, J.J. (1997) The integrase family of tyrosine recombinases: evolution of a conserved active site domain. Nucleic Acids Res. 25: 3605-3614.

Furste, J.P., Pansegrau, W., Ziegelin, G., Kroger, M., and Lanka, E. (1989) Conjungative transfer of promiscuous IncP plasmids: interaction of plasmid-encoded products with the transfer origin. Proc Natl Acad Sci U S A 86: 1771-1775.

Ghinet, M.G., Bordeleau, E., Beaudin, J., Brzezinski, R., Roy, S., and Burrus, V. (2011) Uncovering the prevalence and diversity of integrating conjugative elements in actinobacteria. PLoS One 6: e27846.

Gray, T.A., Krywy, J.A., Harold, J., Palumbo, M.J., and Derbyshire, K.M. (2013) Distributive conjugal transfer in Mycobacteria generatesprogeny with meiotic-like genomewide mosaicism, allowing mapping of a mating identity locus. PloS Biol. 11: e1001602.

Grohmann, E. (2010) Autonomous plasmid-like replication of Bacillus ICEBs1: A general feature of integrative conjugative elements? MicroCommentary. Mol Microbiol 75: 261-263.

Guglielmini, J., Quintais, L., Garcillán-Barcia, M.P., de la Cruz, F., and Rocha, E.P.C. (2011) The repertoire of ice in 
prokaryotes underscores the unity, diversity, and ubiquity of conjugation. PLoS Genet. 7: e1002222.

Johnson, C.M., and Grossman, A.D. (2015) Integrative and conjugative elements (ICEs): What they do and how they work. Annu Rev Genet 49: 577-601.

Koraimann, G., and Wagner, M.A. (2014) Social behavior and decision making in bacterial conjugation. Front Cell Infect Microbiol 4: 1-7.

Lee, C.A., Babic, A., and Grossman, A.D. (2010) Autonomous plasmid-like replication of a conjugative transposon. Mol Microbiol 75: 268-279.

Lewis, J.A., and Hatfull, G.F. (2001) Control of directionality in integrase-mediated recombinatio: examination of recombination directionality factors (RDFs) including $X$ is and Cox proteins. Nucleic Acids Res. 29: 2205-2216.

Marra, D., and Scott, J.R. (1999) Regulation of excision of the conjugative transposon Tn916. Mol Microbiol 31: 609-621.

Ochman, H., Lawrence, J.G., and Groisman, E.A. (2000) Lateral gene transfer and the nature of bacterial innovation. Nature 405: 299-304.

Ohtani, N., Tomita, M., and Itaya, M. (2010) An extreme thermophile, Thermus thermophilus, is a polyploid bacterium. $J$ Bacteriol 192: 5499-5505.

Picher, Á.J., Budeus, B., Wafzig, O., Krüger, C., GarcíaGómez, S., Martínez-Jiménez, M.I., et al. (2016) TruePrime is a novel method for whole-genome amplification from single cells based on TthPrimPol. Nat Commun 7: 13296.

Sentchilo, V., Czechowska, K., Pradervand, N., Minoia, M., Miyazaki, R., and Van Der Meer, J.R. (2009) Intracellular excision and reintegration dynamics of the ICEclc genomic island of Pseudomonas knackmussii sp. strain B13. Mol Microbiol 72: 1293-1306.
Smillie, C., Garcillan-Barcia, M.P., Francia, M.V., Rocha, E. P.C., and de la Cruz, F. (2010) Mobility of plasmids. Microbiol Mol Biol Rev 74: 434-452.

Song, B., Shoemaker, N.B., Gardner, J.F., and Salyers, A.A. (2007) Integration site selection by the bacteroides conjugative transposon CTnBST. J Bacteriol 189: 6594-6601.

Thoma, L., and Muth, G. (2015) The conjugative DNAtransfer apparatus of Streptomyces. Int $J$ Med Microbiol 305: 224-229.

Verdú, C., Sanchez, E., Ortega, C., Hidalgo, A., Berenguer, J., and Mencía, M. (2019) A modular vector toolkit with a tailored set of thermosensors to regulate gene expression in Thermus thermophilus. ACS Omega 4: 14626-14632.

Wood, M.M., and Gardner, J.F. (2015) The integration and excision of CTnDOT. Mob DNA III 3: 183-198.

Wozniak, R.A.F., and Waldor, M.K. (2010) Integrative and conjugative elements:mosaic mobile genetic elements enabling dynamic lateral gene flow. Nat Rev Microbiol 8: 552-563.

Wright, L.D., and Grossman, A.D. (2016) Autonomous replication of the conjugative transposon Tn916. J Bacteriol 198: 3355-3366.

Zhu, Z., Guan, S., Robinson, D., El Fezzazi, H., Quimby, A., and $\mathrm{Xu}, \mathrm{S} . \mathrm{Y}$. (2014) Characterization of cleavage intermediate and star sites of RM.Tth111II. Sci Rep. 4: 1-11.

\section{Supporting Information}

Additional Supporting Information may be found in the online version of this article at the publisher's web-site:

Appendix S1: SUPPLEMENTARY INFORMATION 